\title{
Analisis Pengaruh Kerapatan Vegetasi Ruang Terbuka Hijau (RTH) Terhadap Intensitas Cahaya Matahari dan Suhu Udara (Studi Kasus: Kota Jambi)
}

\author{
Anggrika Riyanti $^{*}$, G.M Saragih ${ }^{2}$, dan Nur Fauziah Zahratu Qolbi ${ }^{3}$ \\ ${ }_{1,2,3}$ Program Studi Teknik Lingkungan, Fakultas Teknik, Universitas Batanghari \\ Jalan Slamet Riyadi, Kota Jambi \\ e-mail: anggrika.riyanti@unbari.ac.id
}

\begin{abstract}
Increasing urban population growth has causing unbalanced development which has a negative impact on green open space. Jambi City has 14.92 ha of green open space. When compared with the area of Jambi City, it is found that green open space is only 8.76\%. One of the impacts of reducing green open space is the increase in air temperature in Jambi City every year. This study aims to analyze the effect of vegetation density on green open space on light intensity and air temperature in Jambi City. The research case studies were in Kota Baru, Telanaipura, and Pasar Jambi Districts which selected based on zoning of green open space covered with a density level of rarely, medium and dense (Regulation of the Director of Planning of the Ministry of Forestry Number 3/2014). The effect of vegetation density on light intensity and air temperature was statistically analyzed using Pearson correlation. The results showed that vegetation density in green open spaces had a significant effect on light intensity with a strong correlation value of 0.704 . Vegetation density also had a significant effect on air temperature with a moderate correlation value of 0.575 .
\end{abstract}

Keywords: Green open space, intensity of sunlight, air temperature.

\section{Pendahuluan}

Meningkatnya pertumbuhan penduduk perkotaan menyebabkan terjadinya pembangunan yang tidak seimbang sehingga berdampak negatif pada beberapa aspek salah satunya kondisi lingkungan. Dalam tahap awal perkembangan kota, sebagian besar lahan merupakan ruang terbuka hijau (RTH). Adanya kebutuhan ruang untuk menampung penduduk dan aktivitasnya, sehingga ruang hijau tersebut cenderung mengalami konversi tata guna lahan menjadi lahan terbangun. Kota Jambi memiliki 671 lokasi RTH dengan luas total RTH di Kota Jambi 14,922 ha (BAPPEDA Kota Jambi, 2018). Apabila dibandingkan dengan luas Kota Jambi yang memiliki luas sekitar $205.38 \mathrm{~km}^{2}$ atau 20.538 ha, diperoleh gambaran bahwa luas RTH publik hanya sekitar $8.76 \%$ dari luas wilayah Kota Jambi (Marhadi dan Hadrah, 2020). Berdasarkan Undang - Undang Nomor 26 Tahun 2006 proporsi RTH pada wilayah kota paling sedikit $30 \%$ dari luas wilayah kota -terbagi menjadi RTH publik minimal 20\% dan RTH privat $10 \%$.

Namun, setiap tahun Kota Jambi mengalami peningkatan suhu. Berdasarkan data Stasiun Meteorologi Sultah Thaha Jambi (2019), selama tiga tahun terakhir terjadi peningkatan suhu setiap tahunnya dimana tahun 2016 sebesar $27,2{ }^{\circ} \mathrm{C}, 2017$ meningkat menjadi $28{ }^{\circ} \mathrm{C}$ dan 2018 menjadi $28,5^{\circ} \mathrm{C}$. Peningkatan suhu ini salah satunya disebabkan peningkatan jumlah penduduk dan tingginya aktivitas masyarakat yang menghasilkan jejak karbon. Selain itu, konversi Ruang Terbuka Hijau menjadi pemukiman, pertokoan dan bangunan lainya juga mengurangi fungsi tumbuhan sebagai penyerap karbon yang mengakibatkan kenaikan suhu di Kota Jambi.

Kemampuan penyerapan pada tanaman merupakan salah satu cara untuk mengurangi emisi $\mathrm{CO}$, salah satunya pada Ruang Terbuka Hijau (RTH). Menurut Suwarna (2020), jumlah emisi $\mathrm{CO}_{2}$ yang dapat diserap oleh RTH di Kota Jambi sebanyak 3.645,6 ton/tahun. Peran vegetasi pada RTH dalam menurunkan suhu udara diperoleh melalui proses fotosintetis yang terjadi pada tumbuhan. Tumbuhan atau vegetasi sangat diperlukan di perkotaan dikarenakan tumbuhan hijau akan menjaring $\mathrm{CO}_{2}$ dan melepas $\mathrm{O}_{2}$ ke udara melalui proses fotosintesis. Penelitian ini bertujuan untuk mengetahui pengaruh kerapatan vegetasi RTH terhadap suhu dan intensitas cahaya di Kota Jambi.

\section{Metode Penelitian}

Teknik pengambilan sampel dalam penelitian ini menggunakan teknik purposive sampling. Data yang diambil pada penelitian ini adalah suhu dan intensitas cahaya matahari menggunakan beberapa alat yaitu Thermometer Digital dan Luxmeter. Pengukuran dilakukan selama 3 minggu berturutturut, dimana pengukuran dilakukan pada hari Senin dan hari Minggu setiap minggunya. Hari Senin merupakan hari kerja dan hari Minggu yang merupakan hari libur. Pengukuran dalam satu hari dilakukan pada kondisi cuaca cerah pada tiga waktu yaitu pagi hari pukul $07.00-08.00 \mathrm{WIB}$, siang hari pukul $12.00-13.00 \mathrm{WIB}$, dan sore hari pukul $17.00-18.00$ WIB.

Lokasi sampling dalam penelitian ini yaitu Kecamatan Kota Baru, Kecamatan Telanaipura dan Kecamatan Pasar Jambi. Penentuan titik lokasi pengambilan sampling ini berdasarkan pada peta tutupan lahan, mengacu pada Peraturan Direktur Planologi Kementrian Kehutanan Nomor 3 Tahun 2014 tentang Petunjuk Teknis Penggambaran dan Penyajian Peta. Lokasi sampling berdasarkan zonasi tutupan lahan ditampilkan pada Tabel 1. 
Tabel 1. Lokasi sampling berdasarkan zonasi tutupan lahan

\begin{tabular}{cccc}
\hline Warna Zonasi & Lokasi Sampling & Kecamatan & Ket \\
\hline Hijau Tua & Hutan Kota M. Sabki & Kota Baru & Tutupan lahan rapat \\
Hijau Tua & Jalur Hijau & Telanaipura & Tutupan lahan rapat \\
Hijau Tua & Taman Makalam & Pasar Jambi & Tutupan lahan rapat \\
Hijau Muda & Taman Remaja & Kota Baru & Tutupan lahan sedang \\
Hijau Muda & Taman Anggrek & Telanaipura & Tutupan lahan sedang \\
Hijau Muda & Taman Simp. Angso Duo & Pasar Jambi & Tutupan lahan sedang \\
Kuning & Taman Jomblo & Kota Baru & Tutupan lahan jarang \\
Kuning & Area Gubernur & Telanaipura & Tutupan lahan jarang \\
Kuning & Taman TP Sriwijaya I & Pasar Jambi & Tutupan lahan jarang \\
\hline
\end{tabular}

Analisis data dilakukan secara statistik menggunakan program SPSS untuk melihat pengaruh antara intensitas cahaya dan suhu terhadap kerapatan vegetasi RTH. Hipotesis penelitian sebagai berikut:

$\mathrm{Ha}=$ Ada hubungan yang signifikan antara variabel intensitas cahaya matahari (x1) dan suhu udara (x2) terhadap kerapatan vegetasi RTH (y).

Ho = Tidak ada hubungan yang signifikan antara variabel intensitas cahaya matahari (x1) dan suhu udara (x2) terhadap kerapatan vegetasi RTH (y).

Dasar Pengambilan Keputusan:

a. Jika nilai Signifikan > 0,05 maka H0 diterima, artinya hubungan antar variabel tidak signifikan.

b. Jika nilai Signifikan < 0,05 maka H0 ditolak, artinya hubungan antar variabel signifikan.

\section{Hasil dan Pembahasan}

\subsection{Intensitas dan Suhu di Kecamatan Kota Baru}

Hasil pengurukuran intensitas cahaya di Kecamatan Kotabaru pada tiga waktu (pagi, siang dan sore hari) menunjukkan intensitas cahaya paling tinggi terjadi pada siang hari sebesar 884,7 lux yang berlokasi di Taman Jomblo. Intensitas cahaya matahari terendah yakni berlokasi di Hutan Kota M. Sabki pada pagi dan sore hari dengan intensitas cahaya pada pagi hari sebesar 288,2 lux (Gambar 1). Sedangkan hasil pengukuran suhu udara paling tinggi juga terjadi pada siang hari sebesar $31^{\circ} \mathrm{C}$ yang berlokasi di Taman Jomblo. Suhu udara terendah yakni berlokasi di Hutan Kota M. Sabki dan Taman Remaja pada pagi dengan suhu udara sebesar $24^{\circ} \mathrm{C}$ (Gambar 2).

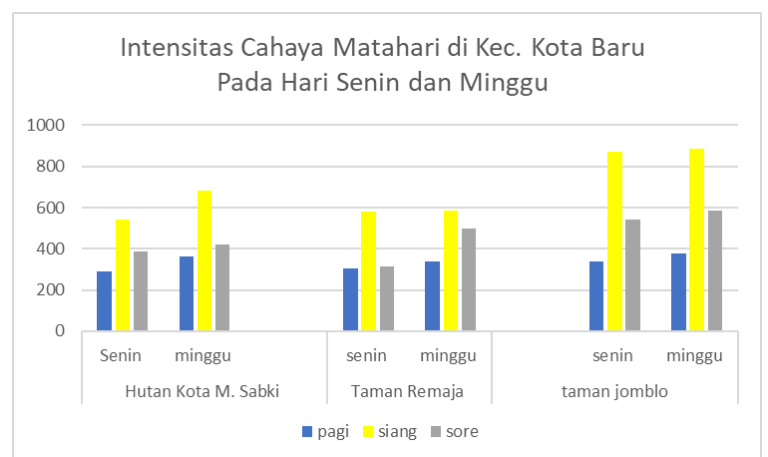

Gambar 1. Hasil pengukuran Intensitas Cahaya di Kecamatan Kota Baru
Suhu Udara di Kec. Kota Baru Pada Hari Senin dan Minggu

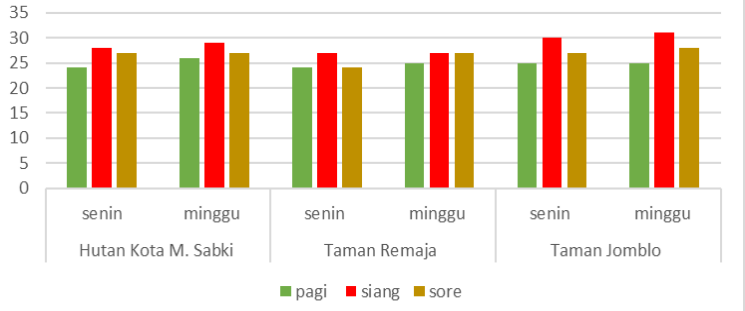

Gambar 2. Hasil pengukuran Suhu Udara di Kec. Kota Baru

\subsection{Intensitas dan Suhu di Kecamatan Telanaipura}

Gambar 3 menunjukkan hasil pengukuran pada Kecamatan Telanaipura intensitas cahaya matahari paling tinggi terjadi pada siang hari sebesar 751,8 lux yang berlokasi di Taman Anggrek. Intensitas cahaya matahari terendah yakni berlokasi di Taman Anggek pada Minggu pagi dengan intensitas cahaya pada pagi hari sebesar 345 lux. Sedangkan Gambar 4 menunjukkan suhu udara pada RTH di Kecamatan Telanaipura paling tinggi terjadi pada siang hari sebesar $29^{\circ} \mathrm{C}$ yang berlokasi di Jalur Hijau, Taman Anggrek dan Area Gubernur. Suhu udara terendah yakni berlokasi di Taman Anggrek pada pagi hari dengan intensitas cahaya sebesar $24^{\circ} \mathrm{C}$.

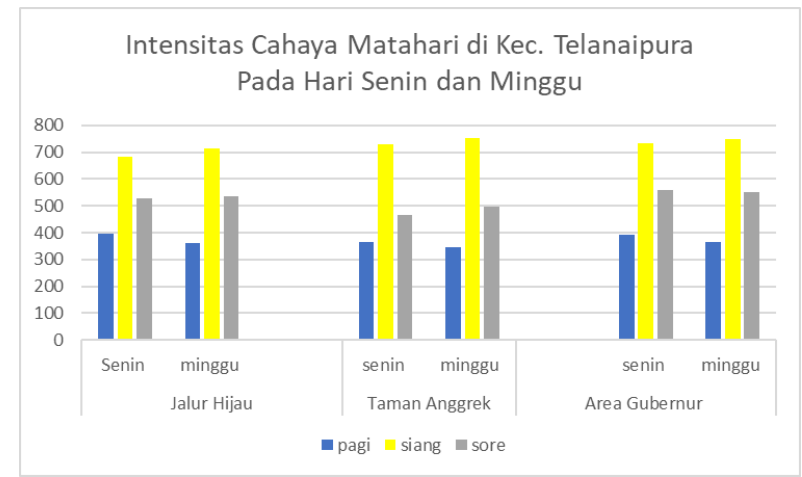

Gambar 3. Intensitas Cahaya di Kec. Telanaipura 


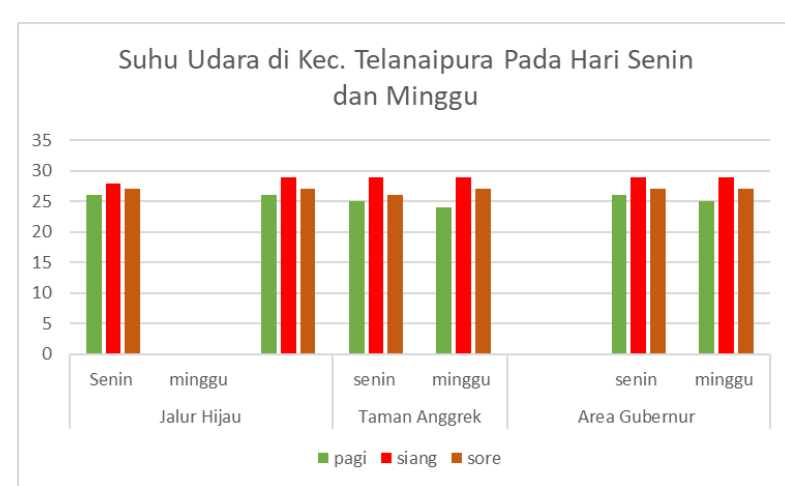

Gambar 4. Grafik Rata- Rata Suhu Udara di Kec. Telanaipura

\subsection{Intensitas dan Suhu di Kecamatan Pasar Jambi}

Hasil pengukuran pada RTH di Kecamatan Pasar Jambi menunjukkan intensitas cahaya di paling tinggi terjadi pada siang hari sebesar 1015,4 lux yang berlokasi di Taman Makalam. Intensitas cahaya matahari terendah yakni berlokasi di Taman Makalam pada pagi hari dengan intensitas cahaya sebesar 355,4 lux. Sedangkan suhu udara paling tinggi terjadi pada siang hari sebesar $31^{\circ} \mathrm{C}$ yang berlokasi di Taman Simpang Makalam. Suhu udara terendah yakni berlokasi di Taman TP Sriwijaya I pada pagi hari dengan suhu udara sebesar $25^{\circ} \mathrm{C}$.

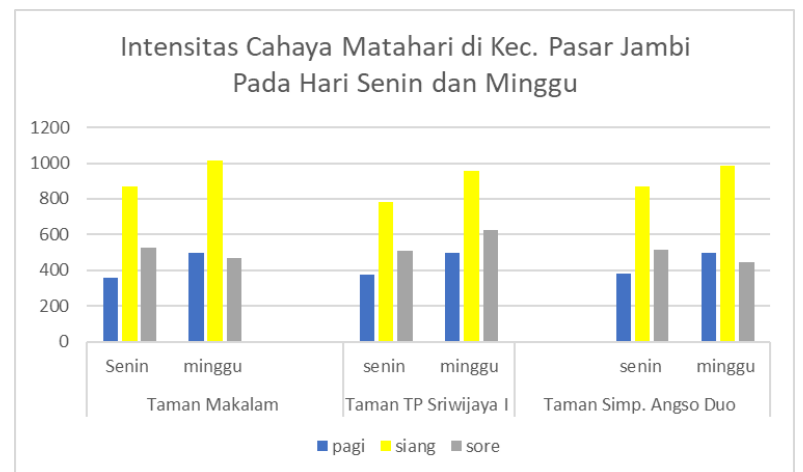

Gambar 5. Intensitas Cahaya di Kec. Pasar Jambi

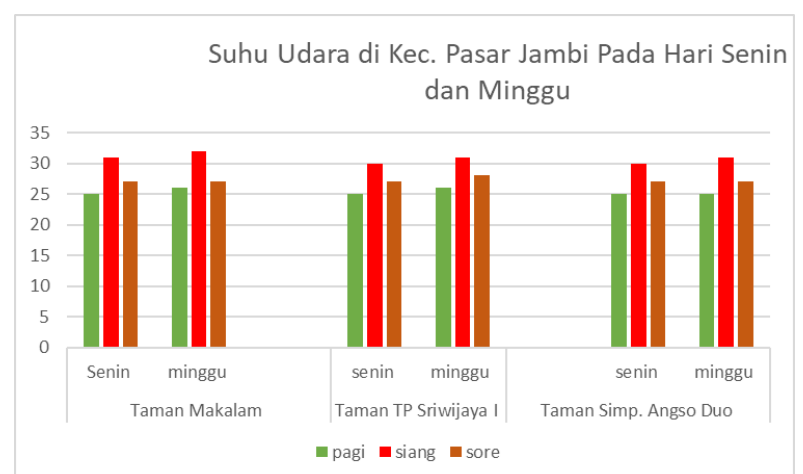

Gambar 6. Grafik Rata- Rata Suhu Udara di Kec. Pasar Jambi.

\subsection{Hasil Uji Korelasi Antara Kerapatan Vegetasi RTH (y) dan Intensitas Cahaya Matahari ( $\left.\mathbf{x}_{1}\right)$}

Berdasarkan data intensitas cahaya matahari dan suhu udara maka dilakukan uji Korelasi Pearson untuk melihat pengaruh antara intensitas cahaya matahari $\left(\mathrm{x}_{1}\right)$ dengan kerapatan vegetasi RTH (y). Hasil analisis korelasi ditampilkan pada Tabel 2.
Tabel 2. Hasil Uji Korelasi Kerapatan Vegetasi RTH terhadap Intensitas Cahaya Matahari

\begin{tabular}{lcc}
\hline & $\begin{array}{c}\text { Kecamatan } \\
\text { Penelitian }\end{array}$ & $\begin{array}{c}\text { Intensitas Cahaya } \\
\text { Matahari }\end{array}$ \\
\hline Pearson Correlation & 1 & 0,704 \\
Sig. (2-tailed) & & 0,003 \\
$\mathrm{~N}$ & 54 & 54 \\
\hline
\end{tabular}

Berdasarkan Tabel 2, besarnya koefisien korelasi (r) antara kerapatan vegetasi terhadap intensitas cahaya matahari dan RTH adalah sebesar 0,704. Hal ini menunjukkan hubungan antar variabel yang kuat dan positif dengan nilai signifikansi 0,003 dimana $0,003<0,05$ yang berarti Ho ditolak dan artinya terdapat pengaruh yang signifikan antara variabel Intensitas cahaya matahari dan kerapatan vegetasi RTH. Koefisien Determinasi antara intensitas cahaya matahari dan kerapatan vegetasi RTH adalah $49,56 \%$ yang artinya intensitas cahaya matahari mempengaruhi sebesar $49,56 \%$ terhadap kerapatan vegetasi RTH.

\subsection{Hasil Uji Korelasi Kerapatan Vegetasi RTH terhadap Suhu Udara}

Hasil uji korelasi antara kerapatan vegetasi dan suhu udara ditampilkan pada Tabel 3.

Tabel 3. Hasil Uji Korelasi Suhu Udara Terhadap Kerapatan Vegetasi RTH

\begin{tabular}{lll}
\hline Kecamatan Penelitian & \multicolumn{2}{l}{ Suhu Udara } \\
\hline Sig. (2-tailed) & 0,005 & \\
N & 54 & 54 \\
Pearson Correlation & 0,575 & 1 \\
\hline
\end{tabular}

Berdasarkan Tabel 3, besarnya koefisien korelasi (r) antara Intensitas cahaya matahari dan kerapatan vegetasi RTH adalah sebesar 0,575. Hal ini menunjukkan hubungan antar variabel yang sedang dan positif dengan nilai signifikansi 0,005 dimana $0,005<0,05$ yang berarti $\mathrm{H} 0$ ditolak dan artinya terdapat pengaruh yang signifikan antara variabel suhu udara $\left(\mathrm{x}_{2}\right)$ dan kerapatan vegetasi RTH $(\mathrm{y})$. Koefisien Determinasi antara suhu udara dan kerapatan vegetasi RTH adalah 33,06\% yang artinya suhu udara mempengaruhi sebesar 33,06\% terhadap kerapatan vegetasi RTH.

Hasil penelitian ini sesuai dengan Zubair (2018) dan Indrawati, dkk (2020) dimana kerapatan vegetasi RTH akan mempengaruhi suhu di suatu wilayah. Ketersediaan RTH berpengaruh besar terhadap suhu udara di perkotaan. Penambahan RTH publik seperti taman kota dan penambahan jumlah vegetasi pada sepanjang jalan protokol serta perawatan secara berkala diharapkan mampu mengurangi kenaikan suhu udara di perkotaan.

\section{Kesimpulan}

Kesimpulan dari penelitian ini adalah kerapatan vegetasi pada ruang terbuka hijau berpengaruh secara signifikan terhadap intensitas cahaya dengan nilai korelasi kuat sebesar 0,704. Kerapatan vegetasi juga berpengaruh secara signifikan terhadap suhu udara dengan nilai korelasi sedang sebesar 0,575 . 


\section{Daftar Pustaka}

Badan Meteorologi, Klimatologi dan Geofisika Kota Jambi. (2019). Iklim Kawasan Jambi.

BAPPEDA Kota Jambi, (2018). Jumlah Luasan Ruang Terbuka Hijau di Kota Jambi.

Dewi A.S, (2017). Pengaruh Intensitas Cahaya Matahari Terhadap Perubahan Suhu, Kelembaban Udara dan Tekanan Udara. Universitas Negeri Jember.

Ernyasi, (2012). Hubungan Iklim Dengan Suhu Udara, Curah Hujan, Kelembaban dan Kecepatan Angin di Jakarta. Universitas Indonesia.

Fatimah, dkk, (2012). Analisis Hubungan Luas Ruang Terbuka Hijau (RTH) dan Perubahan Suhu di Kota Palu. IPB.

Marhadi dan Hadrah. (2020). Ketersediaan Ruang Terbuka Hijau (RTH) Taman dan Hutan Kota di Kota Jambi. Jurnal Daur Lingkungan, 3(1): 13-17.

Suwarna, M. dkk. (2020). Analisis Kebutuhan Ruang Terbuka Hijau Sebagai Penyerap Gas $\mathrm{CO}_{2}$ (Studi Kasus: Kecamatan Telanaipura Kota Jambi). Jurnal Daur Lingkungan, 3(1): 18-22.

Zubair, A.M. (2017). Pengaruh Ketersediaan Ruang Terbuka Hijau Terhadap Iklim Mikro di Kota Makassar. Jurnal Teknik Lingkungan. Universitas Hassanuddin Makassar.

Indrawati, D.M., dkk. (2020). Analisis Pengaruh Kerapatan Vegetasi Terhadap Suhu Permukaan dan Keterkaitannya Dengan Fenomena UHI. Jurnal Media Komunikasi Geografi, 21(1): 99-109.

Iqlimah I.T, (2010). Variasi Suhu dan Kelembaban Udara di Taman Suropati dan Sekitarnya. Universitas Indonesia.

Peraturan Direktur Planologi Kementrian Kehutanan Nomor 3 Tahun 2014 tentang Petunjuk Teknis Penggambaran dan Penyajian Peta. 